\title{
A pesquisa em artes do corpo na acadêmia
}

Renato Ferracini *

Universidade Estadual de Campinas

\begin{abstract}
Resumo
Esse artigo busca pensar características específicas da produção de pesquisa acadêmica nas artes presencias a partir de seus aspectos processuais, composicionais, ontogenéticos, experienciais e de seu compartilhamento tomando como base o conceito de ética e corpo em Espinosa.
\end{abstract}

\section{Palavras-Chave}

Pesquisa ; Ética; Corpo; Composição.

\section{Research in body arts at the academy}

Abstract

This paper tries to think specific characteristics of academic research production in body arts from their procedural, compositional, ontogenetic, experiential and sharing aspects based on the concept of ethics and body in Espinosa.

\section{Keywords}

Research; Ethics; Body; Composition.

* Ator-Pesquisador e atual Coordenador Associado do LUME - Núcleo Interdisciplinar de Pesquisas Teatrais UNICAMP; Professor Pleno e Orientador do Programa de Pós-Graduação em Artes da Cena - IA - UNICAMP. 
O livro O que é a Filosofia? de Deleuze e Guattari (1992) dilui as hierarquias históricas e as capturas ligadas ao senso-comum que diz: a ciência pensa e a arte é o lugar da criação. A obra relaciona pensamento e criação numa fórmula simples: pensamento=criação. Segundo os autores, a ciência cria funções, a filosofia cria conceitos, a arte cria sensações. Todas elas criam, todas elas pensam, sem qualquer hierarquia entre si. Mas por que essa obra nos auxilia a pensar a pesquisa artística na universidade? Por uma questão óbvia: já que a arte gera pensamento por sensações num território de singularidade única, esse plano não necessita de nenhuma corroboração para sua existência e/ou potência própria. Afirmamos, portanto, uma autonomia ontológica do fazer artístico como terreno único e potente de um pensamento/criação. Um pensar/criar que não necessita de um aval científico ou conceitual para sua plena realização. A arte não necessita de nenhum "pensamento sobre", pois ela é pensamento em si. Assim, a aliança entre o pensamento conceitual escrito e 0 acontecimento estético não deveria ser da ordem do PENSAR SOBRE (realizarei um pensamento sobre essa cena) mas deve estar no plano do PENSAR COM (realizarei um pensamento com essa cena). A ideia do PENSAR SOBRE pode nos levar à imagem equivocada do pensamento conceitual escrito ser 0 aval do acontecimento presencial estético ou, pior, sua suposta tradução conceitual. Esse PENSAR SOBRE pode operar no nível da relação hierárquica dessas relações, já que o acontecimento presencial estético no ato do pensar sobre - não geraria um pensamento mas apenas um acontecimento. Estamos novamente capturados aqui em uma área compartimentalizada na qual o conceito produz pensamento e a arte produz criação. Ao negar esse achatamento e hierarquização o PENSAR COM aparece como ação que mantém a autonomia criativa tanto do acontecimento presencial estético como da conceituação de cunho escrito. O PENSAR COM opera uma aliança entre os termos sem cair numa suposta hierarquia entre eles. Ao PENSAR COM, afirma-se o caráter criativo de ambos os planos e também garante o modo de pensamento autônomo que cada superfície possui. Ambos são criativos, ambos são 
pensamentos! Essa aliança calcada no COM borra as fronteiras entre uma e outra forma de expressão (conceitual e estética) e ao mesmo tempo mantém seus contornos em tensão. É justamente no conflito destas autonomias criativas que coexiste por um lado a possibilidade de reflexão e por outro a impossibilidade de tradução direta entre os termos. 0 PENSAR COM se territorializa nas bordas desse conflito, nas frestas de impossibilidade, nos não-lugares de coincidência. A pesquisa em arte na universidade alimenta-se dessa tensão, desse conflito, dessa postura, desse ethos dinâmico entre duas formas de pensamento/criação que produzem alianças mas não se reduzem uma na outra.

Tomemos o corpo como a potência criativa aberta que dá suporte aos acontecimentos estéticos presenciais. Todo corpo, para além de sua estrutura biológica, social ou histórica, se recria criativamente na recomposição de todas suas camadas de forças e formas em atravessamento. Um corpo, assim, possui a potência de sua própria desterritorialização e autopoiése (Matura e Varela, 1997). Não somente na arte, mas NA VIDA os corpos criam e se recriam. 0 pensar, assim como 0 criar, somente se efetuam se atrelados a uma intensificação positiva da vida em sua rede de relações e afetos. 0 ato de criar, assim como o de pensar, precisaria proporcionar outras formas de sensação, outras maneiras de percepção, outros modos de existência. Na arte presencial esse corpo seria tão somente a afirmação e a intensificação dessa ação de auto-recriação em um plano híbrido e único de poética, ética e política.

Quando falamos de inventividade não nos referimos ao novo, mas na disposição de inventar outros modos de composição. Inventar, nesse caso, seria uma capacidade composicional cuja postura ético-política propõe ampliação de potência de todas as partes envolvidas nessa mesma composição. E inferir de forma genérica que 0 artista e esse campo específico das artes presenciais já solucionou o problema da composição e já aboliu os protocolos expressivos alçando seu fazer numa suposta liberdade criativa é uma visão absolutamente romântica da arte presencial. 
Posso dizer que as artes presenciais são, como todas as outras áreas, um campo no qual os protocolos, enquanto modos de operação de processos criativos, se colocam de uma forma muito contundente, mesmo que sejam protocolos temporários. Digo, ainda, que esses protocolos mediam a maioria dos modos de produção cênica na atualidade, ou seja, existe um modo de criação cênica em que são determinadas as funções dos atores, diretores, espaço, texto, luz, som, dramaturgia cênica e até mesmo modos organizados de recepção, de "fazer sentir" e até mesmo um modo protocolar de "fazer pensar". Existe uma construção mediada, transversalizada e hierarquizada pelos protocolos. É uma composição? Sim, é uma composição. Mas uma composição reconhecida, normatizada, organizada, capturada e que busca afirmar o mesmo. Vale afirmar que a questão não é negar os protocolos enquanto modos de fazer pois são partes necessárias na composição. Impossível realizar um concerto de Rachmaninoff com apenas duas aulas de piano mesmo que tenhamos nascido pra ser pianista. Se não praticarmos o processo de reconstrução para que as mãos e o corpo com um todo se componha com o piano, não tocaremos Rachmaninoff. Os protocolos, enquanto técnicas formalizadas e modos de fazer, são necessários. O problema é: como colocar esses protocolos em composição inventiva? Essa é A pergunta para as artes e para todas aquelas profissões que necessitam de protocolos e de procedimentos - mas não acredito que haja algum ofício que deles abram mão de forma definitiva.

Seria um grave erro buscar uma resposta definitiva para essa questão, pois essa postura nos levaria a uma espécie de meta-protocolo. Esse assunto, antes de nos levar a possíveis respostas, nos insere diretamente num campo ético-político (ou ainda ético-micro-político) inventivo de outros modos possíveis de composição. Investigar esses outros modos composicionais posiciona nosso foco de atenção nos elementos processuais. Talvez sejam os próprios processos composicionais que nos darão pistas sobre seus outros modos de operação. Em outras palavras: é o próprio processo de criar um evento cênico que engendra o corpo- 
espetáculo. Para deixar ainda mais complexo: a obra final é ela mesmo um processo.

Um exemplo do que estou chamando de processo ou de composição em ato fora do contexto das artes presenciais para nos proporcionar o tão sonhado, e impossível, distanciamento do objeto: compramos um livro sobre como surfar. O lemos do início ao fim. Além do livro ainda temos um conhecimento muito profundo do atrito da prancha com a água e do corpo com o vento. Após muitos cálculos exatos, sabemos os tamanhos das ondas e a velocidade do vento naquele momento e realizamos um estudo minucioso sobre o equilíbrio dos corpos. Munido de todas essas informações, pegamos nossa prancha e surfamos? Não! Por que? Porque existe uma espécie de "conhecimento" presencial do processo da ação de surfar que se dá na composição em ato entre a prancha, a onda, o vento, 0 corpo, o equilíbrio, o atrito e todo o treinamento técnico, erros e acertos anteriores da busca desse surfar. Existe a invenção em ato de um corpoprancha-vento-onda-técnica-do-surf que nos faz surfar e que se dá na composição entre as materialidades de suas partes, tão complexas quanto a própria composição: antes da invenção do corpo-ato-de-surfar precisamos ter treinado, construído esse outro corpo enquanto técnica (ou protocolo) do surfar; precisaríamos da prancha, da onda e do vento porque sem esses elementos não surfamos. Esses artefatos estão dispersos, e portanto, precisamos construir e compor um só corpo com todos eles. Composição é o ato ontogenético da ação; uma ontogênese da ação em ato. E é nesse sentido que a composição é um processo; um processo que podemos chamar de conhecimento e que emerge da ação de experimentação gerando efeitos de presença. Mas o que interessa não são os efeitos de presença em si mas aqueles que possuam o ethos de uma relação intensificada das partes que amplie qualitativamente a capacidade de potência dessas mesmas partes envolvidas.

O grande problema que se coloca é justamente que essa ontogênese de ação em ator não passa por uma síntese racional seja ela conceitual ou 
científica. Esse plano somente se efetua nele mesmo, ou seja, o pensamento do plano de experienciação somente se dá na sua própria ontogênese. A pesquisa em arte presencial, portanto, somente é possível no mergulho desse/nesse plano de experiência. $O$ conceito de experiência não está de forma alguma atrelado nem a uma experiência como acúmulo de conhecimento (experiência em um determinado assunto) nem como um dispositivo de prova ou comprovação (experiência científica). Para pensar experiência nesse território devemos assentá-la no deslocamento do conceito de sujeito individual. Tomando como base o pensamento de Espinosa, o homem-sujeito deveria ser pensado não no plano de uma autonomia plena com suas vontades e intenções racionais, mas como um grau de potência de afetar e ser afetado com seu corpo não cindido entre corpo-espírito ou corpo-mente. O que eu sou, a definição de homem ou sujeito não passaria mais pelo cristalizador verbo de definição "é" (eu sou), mas pela relação dinâmica da capacidade que temos de afetar e sermos afetados enquanto corpos, ou seja, o "é" substituído pela capacidade de relação e composição com as forças de fora e de dentro que nos atravessam. Mas como saber compor com forças que ampliam nossa capacidade (afetos alegres de Espinosa) ou com forças que diminuem nossa capacidade de ação (afetos tristes de Espinosa)? Qual a capacidade de composição com essas forças? Ou numa pergunta típica de Espinosa: o que pode nosso corpo enquanto potência de afetar e ser afetado? Como nosso corpo compõe com esse plano dinâmico de forças?

A resposta a essas perguntas não passam pela racionalização e/ou categorização das relações dessas forças (quais são boas ou más no aspecto moral), mas pela experiência de composição com elas. Portanto, estar inserido num plano de experiência é estar aberto, poroso e receptivo para os afetos que essa dinâmica contém e ao mesmo tempo compor ativamente com esse plano de forças buscando, de forma ética, realizar ampliação de potência de ação e nisso compor outros modos de existência mais ativos e potentes - mais alegres diria Espinosa. Um plano de experiências não passa somente pelo sujeito que experimenta, mas 0 
sujeito - pensado aqui enquanto dinâmica de subjetivação - busca composições com essa cartografia de forças na qual ele é tão somente uma linha que compõe esse plano cartográfico, mas que pode gerar diferenças qualitativas, criações e recriações nessa composição. Dessa forma, não é o sujeito que cria a experiência, mas o sujeito é lançado em diferenciação continua pelo plano da experiência. Paradoxalmente o plano de experiência pré-existe ao sujeito, mas o sujeito sempre o cria e o recria em sua capacidade de composição de afetos e ao recriá-lo se compõe em outrosujeito. Outra questão é que o plano de experiência é movido por tensões entre suas linhas e elementos sem qualquer previsão a priori de como a experiência vai terminar ou como o irá se reconfigurar em sua recomposição. Um plano de experiências será sempre dinâmico, imprevisível e metaestável e jamais teleológico. Um território com uma cartografia dinâmica de forças, uma ética de composição de forças que determinam aumentos ou diminuições de potência de ação.

Assim, a pesquisa em arte presencial deveria estar fincada numa práxis da experiência enquanto plano autônomo de pensamento. Dessa forma, abre novas perspectivas e deslocamentos ontológicos, epistemológicos, metodológicos que somente a afirmação de sua autonomia e liberdade em relação ao conceito e a ciência podem proporcionar. A pesquisa em arte amplia em muito o pensamento científico e conceitual, pois ao se enraizar no plano de experiência, no aspecto processual e na ontogênese em ato da ação, trabalha em um paradoxo constante de uma invisibilidade visível, de uma concretude do virtual, de um plano de experiência para além ou aquém do sujeito que experiencia. Isso não significa em absoluto um fechamento endógeno da arte, muito pelo contrário. A partir do momento que sua autonomia de pensamento se assenta, o conceito e mesmo as ciência poderiam gerar alianças com a arte de uma maneira absolutamente potente. Não mais o conceito ou a ciência como corroboradores da arte presencial, mas essas criações/pensamentos em um jogo constante com a arte para gerar nessas fricções e tensões outros modos de sensação, de 
inteligibilidade, de racionalidade, enfim, outros modos de existir que sejam compartilhados.

Talvez o que caracterize a pesquisa em artes presenciais na universidade seja, portanto, o foco nesses quatro campos: 1) a composição, 2) 0 processual, 3) a ontogênese da ação em ato e o 4) o compartilhamento. E se tomarmos esses quatro campos como nodais, a pesquisa em artes presenciais na universidade poderia ser definida como 0 compartilhamento do processos composicionais de ontogêneses de ação em ato. E, novamente, a palavra compartilhamento nos remete a busca de uma relação. Mas não de qualquer relação, ou qualquer experiência, mas um compartilhamento que, já que gerador de conhecimento, é potencializador pois, busca, ou deveria buscar, uma ampliação de intensidade e de potência das partes envolvidas nessa mesma relação. Falar em compartilhamento da pesquisa na busca de geração de conhecimento no campo artístico é, dessa forma, resvalar ou dizer de uma postura ética e política, pois adentramos aqui no campo do coletivo.

Esse ethos-político, obviamente, existe no campo artístico fora do âmbito acadêmico. Pensemos a obra como um corpo, um corpo-obra com partescorpos complexos envolvidos em sua composição. E corpo aqui deve ser pensado no sentido de Espinosa que o define como uma relação das partes envolvidas. Relembrando: a ética de Espinosa nos ensina que se a relação das partes num corpo dado (seja o corpo singular, seja o corpo social, o corpo-cidade etc) amplia de forma positiva a ação no mundo de todas as partes envolvidas, essa composição gera alegria. Ora, claramente verificamos que há composições espetaculares dentro do âmbito da arte presencial, e fora do campo acadêmico, que gera o que aqui chamamos de alegria: uma potencialização das partes envolvidas (ator, publico, encenação, luz, som, musica, figurinos, etc). Dentro do âmbito acadêmico essa busca é exatamente a mesma enquanto criação da um processo prático, mas partes extrínsecas à ele, e imanentes à ação de pesquisa 
acadêmica, são acopladas: documentação do processo; desvelamento de dificuldades, impossibilidades, insights e conquistas; a busca de uma narratividade que se acople ao processo de criação e ao fluxo de experiências por ela gerada; diálogos diretos ou indiretos com outros pesquisadores que buscam e se inserem em campos problemáticos afins; enfim, várias partes se acoplam ao processo prático e que, na composição geral, deveriam buscar a ampliação positiva de potência de todas as partes envolvidas. Em última instância, a pesquisa acadêmica no campo dos processos de prática, pensada como esse corpo composto de partes complexas compartilhada em vários âmbitos, gera o que podemos chamar de alegria ampliada, já que partes extrínsecas compartilháveis são a ela somadas gerando uma dupla coletivização tanto dos processos de prática como de seu campo extrínseco. Dessa forma o corpo da pesquisa acadêmica aumenta sua complexidade da composição pois alarga as partes envolvidas na produção de conhecimento, ampliando, assim, sua coletivização. Podemos afirmar que uma pesquisa acadêmica, no campo artístico, intensifica a potência política e ética da arte presencial, dilata sua ação de coletivização e gera mais alegria (aquela de Espinosa), mesmo com todas as tensões intrínsecas ao campo arte/academia.

\section{Referências}

DELEUZE, Gilles e GUATTARI. O que é Filosofia? São Paulo: editora 34, 1992. ESPINOSA, Bento de. Ética. Lisboa: Relógio D’agua: 1992.

MATURANA, Humberto, e VARELA, Francisco. De máquinas e seres-vivos Autopoiése - A organização do vivo. Trad. Juan Açuña Llorens. Porto Alegre: Artes Médicas, 1997. 